\title{
Considerations on using a lightpen-interactive system with young children
}

\author{
S. E. AVONS, M. C. BEVERIDGE, A. T. HICKMAN, and G. J. HITCH \\ Departments of Psychology and Education, University of Manchester, Manchester M13 9PL, England
}

\begin{abstract}
The lightpen is a simple interactive device allowing easy communication between a naive user and a computer. Very young children (4-6 years old) can use a lightpen interactively to pick out targets displayed on a VDU. Accuracy of target selection and stability of pointing with the lightpen was measured in these young children, and also in an older group of children (10-11 years old), who showed superior performance on both measures. In the younger group, both postural factors and physical fatigue sometimes affected lightpen handling. However, children of both age groups failed to compensate for parallax near the edges of the curved display screen. Recommendations are made for the programming and design of lightpen-interactive displays.
\end{abstract}

This article considers the use of a lightpen as an input device to a microcomputer via a raster display. The lightpen is perhaps the simplest interactive device for naive users. It requires only sufficient dexterity to hold the instrument and the natural ostensive action of pointing it at a select feature of the display. Despite its appeal, there appear to have been few reports to date of human performance and computer interaction using the lightpen. Goodwin (1975) reported that cursor positioning was faster under lightpen control than when guided by a rather ill-adapted keyboard. However, the implications of Goodwin's study are limited to the hardware used and the particular mode of lightpen programming.

The aim here is to explore utilization of a lightpeninteractive microcomputer system to obtain behavioral measures from very young primary school children. We are concerned not merely with lightpen characteristics and programming, but also with the handling capabilities of such young subjects, since this is a major determinant of the utility of this interactive device.

\section{Programming Considerations}

for Ligh tpen In teraction

The lightpen is a directionally photosensitive device used in conjunction with a spatially distributed patterned light source, such as a cathode ray tube. When it is pointed at a region of a visual display, a binary signal is sent to the controlling device, indicating that the lightpen either detects light (is activated) or does not.

The interactive use of the lightpen depends on selecting one region of a visual display from a number

The authors are co-workers on the Microprocessors in Education research project at the University of Manchester. We thank the Leverhulme Trust for financial support, the staff of Chorlton Church of England Primary School for their cooperation, and L. Farrell for exquisitely machining the collimator. Copies of reprints are available from S. E. Avons, Department of Psychology, University of Manchester, Oxford Road, Manchester M13 9PL, England. of possible regions. The problem for the controlling device is to identify the region of the screen selected by the user. With raster displays, this process of lightpen location takes place indirectly through software polling. The display must include a number of discrete bright areas potentially visible to the lightpen; these elements then provide the alternatives for selection. The program must search this array of elements and determine which of them, if any, is activating the lightpen. It does this by selectively turning the elements on and off and examining the lightpen status after each change.

The simplest strategy to determine lightpen position is sequential testing of individual array elements. For small numbers of alternatives, this is a convenient method, quick in operation and easy to program. However, with a large number of displayed elements, sequen. tial testing is slow. Faster selection can be achieved by testing the alternatives in successive binary subdivisions. Using this method, when the lightpen is initially activated, the first half of the elements are erased together. If the lightpen is then deactivated (and reactivated when the elements are subsequently redrawn), then it must be pointing at one element in this subset. The first half is then subdivided, and the first quarter of the total number of elements is tested in the next stage. If a test fails, then it is repeated on the other half of that binary division. This check is not really necessary, but without it the accidental failure of a test, for example due to lightpen movement, will result in a spurious element selection. Depending on the speed with which elements can be drawn and erased, this method may be quicker than the sequential test procedure if there are more than eight alternatives. A BASIC subroutine that searches a linear array by this method is listed in the appendix.

Although selection from more than eight alternatives is unusual, there are some circumstances in which it may be useful to do this. We have been using a lightpeninteractive display to collect ratings of children's judgments of physical quantities. This requires a linear 
rating scale with a large number of categories. For example, Anderson and Cuneo (1978) have successfully used a 19-point rating scale with children as young as 4 years of age to explore conservation of area and liquid quantity. Their rating scale consisted of a row of 19 circles, between two endpoints, which were pictured faces. We adapted this rating scale for computerized presentation using a lightpen to obtain readings. Some observations arising from the use of this scale are given in the general discussion.

\section{Lightpen Characteristics}

The lightpen used here (3G Company, Gaston, Oregon) was one with a relatively wide field of view. The chief advantage of this lies in the integration of energy from a large screen area, permitting lightpen sensitivity at low luminance levels. The disadvantage is the restriction this imposes on the spatial selectivity of the device. To improve selectivity at the cost of some sensitivity, it is easy to supply the lightpen with a collimator. The one used here was extemporized from an old ball-point pen top, machined to fit snugly over the end of the lightpen and drilled with a hole of $3-\mathrm{mm}$ diameter to allow light to pass. The loss of sensitivity was compensated for by adjusting the amplification of the photodiode signal, and also screen brightness and contrast. Measurements taken using a scanning display of the type described below indicated that the effective field, sensitive to the lightpen placed in contact with the monitor screen, was reduced from about $16 \mathrm{~mm}$ to $5 \mathrm{~mm}$ by collimation.

\section{LIGHTPEN HANDLING BY CHILDREN}

This section describes an investigation of the lightpen handling ability of two cohorts of primary school children. In designing a lightpen-sensitive display, several factors must be considered. First, the target area must be large enough that the user can effectively position the lightpen over the target. Second, potential targets should be spaced far enough apart that only one element at a time may activate the lightpen. Third, the lightpen should be read as quickly as possible, to speed the interaction and reduce problems arising from user fatigue. Some consideration must also be given to the user's posture with respect to the layout of the display. This factor was not investigated here, but informal observations and some of the results underlined its importance.

Thus limitations on the design of lightpen-interactive displays arise from the handling capabilities of the user, as well as from the physical characteristics of the input device. Handling capability is determined by manipulative skill, aiming accuracy, and manual steadiness, which may be considered to vary with age. In this experiment, we used young children from two age groups that should differ with respect to these characteristics, and we explored the consequences for the design of interactive displays. A lightpen location test was devised to investigate lightpen handling. This test measured accuracy in pointing the lightpen at a target and steadiness in holding the lightpen in a fixed position over a period of several seconds.

\section{Method}

Subjects. Two age groups of 12 primary school children participated, each group consisting of 6 boys and 6 girls. The younger children had a mean age of 5 years 2 months, and the older group had a mean age of 10 years 10 months.

Apparatus and Materials. Measurements of lightpen handling were made with an Apple II microcomputer that was modified to allow the presentation of stimuli synchronized to a raster display (Cavanagh \& Anstis, 1980). The programs were written in BASIC and then compiled using the Microsoft TASC compiler, to run at faster speeds. All stimuli were displayed on a standard 16-in. monochrome video monitor (Sanyo VM4215) using the high-resolution graphics facility. With this combination, 1 screen unit corresponded to approximately $1 \mathrm{~mm}$ in the horizontal and vertical directions.

The experiments were conducted with the subject seated so that the center of the screen was approximately at eye level; the screen was positioned so that the subject could easily reach and touch it with the lightpen in his or her preferred hand. The target consisted of a white $20-\mathrm{mm}$ square displayed on the screen, with a small black cross at its center. The task was to place the lightpen over the black cross and to hold it steadily in position while two readings of the lightpen position were taken. When first positioned over the target, the lightpen was activated; the target was then erased and the lightpen location was determined. This was done by drawing a succession of vertical lines, sweeping across the target area from the left periphery across the center out toward the right. After each line was drawn, the program waited for two raster cycles and then examined the lightpen. If the lightpen was activated, the horizontal coordinate of the last line drawn was noted. The screen was then cleared and the process was repeated, this time with a bright region sweeping across the target area from a different compass direction. The target area was therefore scanned four times, in the directions left to right, right to left, top to bottom, and bottom to top. The location of the lightpen is estimated by averaging both the left and right and the top and bottom locations in the field.

This process of reading the lightpen position lasted about $2.5 \mathrm{sec}$; there then followed a $2-\mathrm{sec}$ delay with a blank screen, and then the measurement was repeated. $A$ tone was sounded to indicate that all the measurements had been taken on that trial.

The two measures obtained from this test were (1) the initial accuracy of placement, measured by the euclidean distance from the target center to the location of the lightpen, as described above, and (2) the shift in lightpen position, measured by the euclidean distance separating the first location reading and the second reading, taken af ter a short delay.

Procedure. Children were tested individually in two sessions of approximately $10 \mathrm{~min}$ duration. In the first session, they were informed about the purpose of the experiment and the function of the lightpen. Then they were given five trials of practice at positioning the lightpen with the target in the center of the screen. Five experimental trials followed, in which the target was placed in various positions midway between the center and each corner of the screen in a random order. The second session consisted of another set of practice and experimental trials.

Children were given verbal instructions throughout. They were told to place the lightpen "right on top of the black cross 
and then hold it steady until the computer tells you to put the pen down" (referring to the tone at the end of the trial).

\section{Results and Discussion}

All children in this study were able to use the lightpen to select targets on the screen. Generally, they found the tool easy to use. After the first session, instructions were redundant, and response to the displays was immediate. Despite this, we observed limitations of performance and age-related differences in handling capability, as detailed below.

The most obvious difference between the two groups was postural. With their longer arms, the older children were able to position the lightpen over the targets with their elbows resting on the table. The younger children could not do this, and so they held the lightpen with an extended, unsupported arm. This was reflected in the greater fatigue reported by the younger children.

Initial placement. For each of five target positions, two readings were obtained of the initial accuracy of lightpen placement on the target. The mean error in placement, averaged over all target positions and both sessions, was $3.0 \mathrm{~mm}$ for the younger age group and $1.7 \mathrm{~mm}$ for the older children. The difference between the two age groups was statistically significant $[F(1,22)=17.15, p<.001]$. However, accuracy on this test did not vary significantly with target position. The distributions of errors made on initial lightpen placement were obtained, and the 95th percentiles were estimated. For the older children, this 95 th percentile corresponded to an error of about $4 \mathrm{~mm}$. The error distribution for the younger age group showed a 95th percentile at about $6.6 \mathrm{~mm}$.

Lightpen drift between first and second readings. The measure here was the euclidean distance between the first and second estimates of the lightpen's position. This measure reflects any tendency to move the lightpen off target when no visual information is available on the screen. The average movement of the lightpen over this $2-\mathrm{sec}$ period was about $3.4 \mathrm{~mm}$ for the younger children and about $1 \mathrm{~mm}$ for the older children. This age difference was again significant $[F(1,22)=15.3, p<.01]$. It seems likely that this is a manifestation of the fatigue experienced by the younger children, or it might reflect a tendency toward uncontrolled movements in the absence of a positional marker on the screen.

\section{GENERAL DISCUSSION}

\section{Recommendations for Lightpen Display Design}

Using the scanning technique, we were able to determine the accuracy of lightpen placement to the nearest millimeter. The distribution of pointing errors suggests practicable lower limits of target diameter, which in turn set an upper limit on the number of alternative choice elements in any one display. Working from the 95th percentiles of initial aiming accuracy, our results suggest practicable lower limits of target diameter of $8 \mathrm{~mm}$ for 11 -year-olds and $13 \mathrm{~mm}$ for younger children. However, factors other than target size may be involved. In our display, the tip diameter of the lightpen was $10 \mathrm{~mm}$ and the white square surrounding the target had sides of $20 \mathrm{~mm}$. The border of the square was thus visible for a short time after the lightpen was placed over the target, and this may have assisted target placement. A concentric surround of this type may considerably improve accuracy of lightpen pointing. The critical minimal spacing between potential target elements would appear to depend on placement error and the field of view of the lightpen. However, we did not investigate target separation systematically.

As noted, postural factors are also of importance. Although the youngest children could touch the screen using the lightpen, they could do this only with an extended and unsupported arm, unlike the older children. This factor gave rise to reports of fatigue among the younger children and to differences in measures of steadiness in holding the lightpen. To avoid fatigue of this kind, attention should be given to the location of targets on the screen, and the work space should be arranged so that, if possible, younger children can work with their arms supported at the elbow. Also, the time taken to determine the lightpen selection should be kept to a minimum.

\section{Parallax Errors}

In addition to the measurement of positional accuracy and steadiness, described above, we asked children to select indicated positions on a linear rating scale that extended across the screen. This scale consisted of a row of 19 elements, which were small pictured faces, measuring $8 \times 11 \mathrm{~mm}$ and separated from each other by only $3 \mathrm{~mm}$. With respect to selectivity, children of both age groups had no difficulty in choosing individual faces, provided that these were in the center of the row. However, a number of children in each group experienced some difficulty in getting the lightpen to select target elements at the ends of the row. This was due to parallax resulting from curvature of the monitor screen. The usual error involved aiming the lightpen on the medial side of these terminal elements.

This parallax error results from a combination of a near viewpoint, necessary in order to be able to reach the display, and the wide separation of the target and lightpen tip by the curved monitor screen. The children who experienced difficulty with parallax generally failed to correct for it; no child was observed to look down the axis of the lightpen to reduce parallax. The simplest way to circumvent this problem is to confine the interactive region of the display to a small, preferably central area of the screen. It is possible that minimal training would 
enable children to avoid this kind of error, and the situation may also be helped by the future introduction of flat VDU screens.

\section{REFERENCES}

Anderson, N. H., \& Cuneo, D. O. The height + width rule in children's judgments of quantity. Journal of Experimental Psychology: General, 1978, 107, 335-378.

Cavanagh, P., \& Anstis, S. M. Visual psychophysics on the Apple II: Getting started. Behavior Research Methods \& Instrumentation, 1980, 12, 614-626.

Goonwrs, N. C. Cursor positioning on an electronic display using lightpen, lightgun or keyboard for three basic tasks. Human Factors, 1975, 17, 289-295.

Appendix

Determination of Lightpen Position by Successive Binary Subdivision

\begin{tabular}{|c|c|}
\hline 1000 & REM ROUTINE TO POLL AN ARRAY OF NT ELEMENTS \\
\hline 1001 & REM USING SUCCESSIVE BINARY SUBDIVISIONS \\
\hline 1010 & REM START \\
\hline 1020 & $J=1: N=N T$ \\
\hline 1030 & IF PEEK (LP) $>127$ GOTO $1030:$ REM WAIT FOR ACTIVATION \\
\hline 1050 & REM START EACH PASS HERE \\
\hline 1060 & IF $\mathbf{J}=\mathbf{N}$ THEN RETURN : REM ITEM FOUND, EXIT \\
\hline 1070 & $\mathrm{IT}=0: \mathrm{REM}$ OTHERWISE RESET TEST COUNTER \\
\hline 1100 & REM RECURSIVE BINARY SEARCH \\
\hline 1110 & $\mathrm{~L}=\mathrm{J}: \mathrm{R}=\mathrm{INT}((\mathrm{N}+\mathrm{J}+1) / 2-1):$ REM TEST L HALF \\
\hline 1120 & GOSUB 1500 \\
\hline 1130 & IF IL $>1$ THEN $N=R:$ GOTO $1060:$ REM LP IN THIS HALF \\
\hline 1140 & $\mathbf{L}=\mathbf{I N T}((\mathbf{N}+\mathbf{J}+1) / 2): \mathbf{R}=\mathbf{N}: \mathbf{R E M}$ TEST R HALF \\
\hline 1150 & GOSUB 1500 \\
\hline 1160 & IF IL $>1$ THEN $\mathrm{J}=\mathrm{L}:$ GOTO $1060:$ REM LP IN THIS HALF \\
\hline 1200 & REM IF THREE SUCCESSIVE TESTS FAIL, START AGAIN \\
\hline 1210 & IT $=$ IT $+1:$ IF IT $>2$ GOTO 1020 \\
\hline 1220 & GOTO $1110:$ REM REPEAT SAME SUBDIVISION \\
\hline 1500 & REM TEST LIGHT PEN WITH CURRENT SUBSET \\
\hline 1510 & $\mathrm{IL}=0$ \\
\hline 1520 & GOSUB 1600 : REM ERASE SUBSET \\
\hline 1530 & IF PEEK (LP) $>127$ THEN IL $=$ IL $+1:$ REM NO LIGHT \\
\hline 1540 & GOSUB $1600:$ REM RE-DRAW SUBSET \\
\hline 1550 & IF PEEK $($ LP $)<128$ THEN IL $=1 L+1:$ REM LIGHT \\
\hline 1560 & RETURN \\
\hline 1600 & REM TURN SUBSET ON OR OFF \\
\hline 1610 & FOR I = L TO R \\
\hline 1620 & XDRAW 1 AT XB + (I-1)*W, YB \\
\hline 1630 & NEXT I \\
\hline 1640 & FOR $K=1$ TO $12:$ NEXT $K:$ REM WAIT AT LEAST 1 RASTER \\
\hline 1650 & RETURN \\
\hline
\end{tabular}

Note-This routine searches a horizontal array of NT elements defined by shape tables. The left half of each subset is examined first, followed by the right half. The value of Location LP indicates the activation state of the lightpen. If a subset of elements in the array controls lightpen activation, then this subset is subdivided on the next pass. The process terminates when the subset contains only one element, and the routine returns the value of this element $(N)$. " $W$ " here is the horizontal spacing; $X B$ and YB are the coordinates of the first element.

(Received for publication June 1, 1982;

revision accepted November 16, 1982.) 